\title{
CD44 regulates blood-brain barrier integrity in response to fluid shear stress.
}

Brandon J. DeOre, B.S.1, Paul P. Partyka, Ph.D1, Fan Fan, MD2, Peter A. Galie, Ph.D 1

1Department of Biomedical Engineering, Rowan University, Glassboro, New Jersey, USA

${ }_{2}$ Department of Pharmacology and Toxicology, University of Mississippi Medical Center,

Jackson, Mississippi, USA 


\begin{abstract}
Fluid shear stress is an important mediator of vascular permeability, yet the molecular mechanisms underlying the response of the blood-brain barrier to shear have yet to be studied in cerebral vasculature despite its importance for brain homeostasis. The goal of this study is to probe components of shear mechanotransduction within the blood-brain barrier to gain a better understanding of pathologies associated with changes in cerebral blood flow including ischemic stroke.Interrogating the effects of shear stress in vivo is complicated by the complexity of factors in the brain parenchyma and the difficulty associated with modulating blood flow regimes.

Recent advances in the ability to mimic the in vivo microenvironment using three-dimensional in vitro models provide a controlled setting to study the response of the blood-brain barrier to shear stress. The in vitro model used in this study is compatible with real-time measurement of barrier function using transendothelial electrical resistance as well as immunocytochemistry and dextran permeability assays. These experiments reveal that there is a threshold level of shear stress required for barrier formation and that the composition of the extracellular matrix, specifically the presence of hyaluronan, dictates the flow response. Gene editing to modulate the expression of CD44, a receptor for hyaluronan that previous studies have identified to be mechanosensitive, demonstrates that the receptor is required for the endothelial response to shear stress. Manipulation of small GTPase activity reveals CD44 activates Rac1 while inhibiting RhoA activation. Additionally, adducin- $\gamma$ localizes to tight junctions in response to shear stress and RhoA inhibition and is required to maintain the barrier._This study identifies specific components of the mechanosensing complex associated with the blood-brain barrier response to fluid shear stress, and therefore illuminates potential targets for barrier manipulation in vivo.
\end{abstract}




\section{Introduction}

Recent studies have established that the integrity of the blood-brain barrier (BBB) is regulated by mechanical stress exerted by blood flow; both fluid shear stress 1 and cyclic strain2 increase the barrier function of in vitro models of cerebral vasculature. Therefore, an understanding of how the $\mathrm{BBB}$ responds to mechanical stress has relevance to neurolopathologies associated with changes to the vasculature and blood flow. One such example is ischemic stroke: an occlusion reduces blood flow prior to reperfusion, and subsequently a no-reflow period occurs as cerebral blood flow is attenuated while vascular permeability simultaneously increases 3-5. Given that previous studies have demonstrated that shear stress stabilizes the barrier, it is likely that the reduction in blood flow causes or at least contributes to $\mathrm{BBB}$ breakdown during the no-reflow period. Yet despite its importance in disease and overall brain homeostasis, the mechanisms underlying the BBB response to fluid shear stress have not yet been investigated in detail.

Several mechanosensing mechanisms of fluid shear stress have been identified in systemic vasculature6-9, including pathways involving the glycocalyx 10, the PECAM-VEGFR2VE-cadherin complex 11, and Notch signaling 12. Yet the differences in structure and function of vasculature and surrounding extracellular matrix in the central nervous system (CNS) insinuate the potential for unique mechanotransduction pathways in the BBB. Endothelial cells in cerebral vasculature form tight junctions, which are complexes of claudins and occludens stabilized by scaffolding proteins including zonula occludin that give rise to the BBB and prevent the transport of blood-borne solutes across the vessel wall into the brain parenchyma. Moreover, the extracellular matrix (ECM) of the CNS is drastically different than other organ systems. The ECM features high concentrations of proteoglycans and glycosaminoglycans, specifically 
hyaluronan (HA)13. Given these differences and the wide variety of mechanotransduction pathways that have been identified in system vasculature14, the present study interrogates a novel mechanism relevant to the $\mathrm{BBB}$.

One common component in several shear-mediated signaling pathways involves the activation of small GTPases8, 15. One small GTPase in particular, RhoA, is also implicated as a regulator of BBB integrity16-19. Previous studies have demonstrated that increased RhoA activity leads to a disassembly of the complexes within cell-cell junctions and subsequent barrier disruption8, 20, 21. Another small GTPase, Rac1, has been associated with stabilization of the $\mathrm{BBB}_{22,23}$, and recent studies have also identified Rac1 activation as a downstream response to fluid shear stress 12. Therefore, this study investigates the effect of shear stress on the activity of both RhoA and Rac1 to gain insight into their role in shear-mediated barrier integrity.

The results described here were produced by a previously described three-dimensional model of the $\mathrm{BBB} 2$. Despite several differences compared to in vivo vasculature, including the lack of a tortuous and branched morphology, absence of immune cells including microglia, and use of culture medium for perfusion instead of blood, the in vitro model provides a controlled setting to study the response to shear stress. Moreover, cells can be genetically or transcriptionally altered prior to incorporation into the device to determine the effects of specific components of the signaling pathway. The device is compatible with dextran-FITC permeability assays as well as immunocytochemistry. A TEER device has also been developed for this microfluidic system, allowing non-invasive measurements of barrier integrity. Overall, the device provides a robust platform to study BBB mechanotransduction.

\section{Methods}




\section{Microfabrication}

Polydimethylsiloxane (PDMS ) microfluidic devices were manufactured as described previously2. Briefly, positive master molds of the devices manufactured using stereolithography (Protolabs) were used to cast negative and positive PDMS master molds which were then used to fabricate the microfluidic device. For monolayer flow experiments, 5-g of PDMS was added to a p100 culture dish and leveled prior to curing. The hydrogel reservoir was etched with 5M sulfuric acid for 90 minutes, thoroughly washed with Millipore water, and subsequently coated with $20 \mu \mathrm{g} / \mathrm{mL}$ collagen for 60 minutes. For monolayer plates, a 40-mm glass cover slip was used to constrain the fluids on the dish. All steps were performed at room temperature. Devices were sterilized under shortwave length ultraviolet light prior to cell seeding.

\section{Cell culture}

All cell experiments were performed with p21-24 HCMEC/d3 (gifted from Dr. Robert Nagele's lab at the Rowan School of Osteopathic Medicine) 3-5 days after thawing and feeding with modified EGM-2 on $1 \%$ gelatin coated tissue culture plates24. Normal human astrocytes (NHA)(Lonza) were thawed at P5 and cultured for 5-10 days prior to cell seeding. Cell cultures were maintained at $37 \mathrm{oC}$ with $5 \% \mathrm{CO}_{2}$ and $95 \%$ relative humidity.

\section{In vitro blood-brain barrier model}

Three-dimensional models of the blood-brain barrier (3D BBB) were fabricated as described previously2. Briefly, a hydrogel composed of $5 \mathrm{mg} / \mathrm{mL}$ type I collagen, $1 \mathrm{mg} / \mathrm{mL} \mathrm{HA}, 1 \mathrm{mg} / \mathrm{mL}$ Matrigel25 were used to fabricate the scaffold. When incorporated into the hydrogel, NHA were seeded at 1 million cells per $\mathrm{mL}$. The gel was injected into the hydrogel reservoir of the device and $180-\mu \mathrm{m}$ needles coated in $0.1 \%$ BSA were inserted prior to polymerization of the hydrogel. The needles were removed after the gel was polymerized leaving two voids in the hydrogel in 
which HCMEC/d3 were injected into one channel at a density of 10 million per mL (15 $\mu \mathrm{L}$ per channel). Channels were incubated for 10 minutes to ensure cell attachment then injected with cells again and inverted for 10 minutes to coat the opposite side. Following cell seeding, channels were either exposed to flow using a linear syringe pump (Kent Scientific) or incubated in static conditions in a 6-well plate. For GTPase activity assays, a larger diameter (1-mm) model was used, which was characterized in previous work26. For the monolayer experiments, the same hydrogel formulation was polymerized on the treated PDMS coated plates under a sterile 40-mm glass coverslip to create a uniform circular hydrogel. Following removal of the cover slip, $\mathrm{HCMEC} / \mathrm{d} 3$ were seeded on the gel at a density of $4 \mathrm{k} / \mathrm{cm} 2$ and allowed to adhere for 30 minutes prior to addition of EGM-2. Monolayers were incubated for 4 days in static culture to ensure confluency, then exposed to fluid shear stress. Fluid shear stress was applied using a 40-mm 1degree cone plate on a rheometer (Waters) for $24-\mathrm{hrs}$ on a Peltier plate set to $37 \mathrm{oC}$. The media was supplemented with HEPES buffer to a final concentration of $10 \mathrm{mM}$ to maintain $\mathrm{pH}$ and sterile Millipore was added to the plate during exposure of flow to counteract evaporative loss27.

\section{Immunocytochemistry}

Following exposure to experimental conditions, vessels were fixed in $4 \%$ paraformaldehyde (Alfa Aesar) for $30 \mathrm{~min}$ at room temperature. Following fixation, the top layer of the device was removed with a razor blade and then the hydrogel was removed from the device and placed in $0.1 \%$ Triton X-100 to permeabilize the cell membrane. Gels were blocked in 5\% normal donkey serum or $3 \%$ BSA for 30 minutes at room temperature followed by incubating overnight with primary antibodies for either HCAM (CD44)(Santa Cruz), glial fibrillary acidic protein (GFAP), adducin- $\gamma$ (ADD3)(ABcam), or zonula occludin-1 (ZO-1)(CST). Following primary incubation, gels were washed three times with PBS for 5 minutes then incubated with the appropriate 
secondary antibody conjugated to Alexa 555 (CST), Alexa 488(Santa Cruz), or Dylight 650

(Thermo Scientific). Gels were counter-stained with DAPI to label nuclei and FITC-phalloidin

for actin. All gels were imaged using a Nikon A-1 confocal scanning microscope.

\section{Permeability testing}

After exposure to experimental conditions, channels were transferred to the stage of an inverted epifluorescent microscope enclosed by an environmental chamber set to $37 \mathrm{C}, 5 \% \mathrm{CO} 2$, and $95 \%$ RH. The channels were perfused with $4-\mathrm{kDa}$ dextran-FITC at a flow rate of $5 \mu \mathrm{L} / \mathrm{min}$ using a syringe pump for 10 minutes, while submerged within culture medium to ensure cell viability. This flow rate was selected to assure fully developed flow throughout the channel and to maintain consistency with previous work2. Images were taken at 30s intervals for 10 minutes, and the diffusion coefficients were established using the following equation from previous work28.

$$
P=\frac{d i}{d t} \frac{r}{2 l_{0}}
$$

Sample numbers of at least $\mathrm{n}=3$ were used to determine the mean and standard deviation of diffusion coefficients for each condition.

\section{Impedance spectroscopy and transendothelial electrical resistance (TEER) measurements}

Impedance measurements were obtained a stingray DS1M12 USB oscilloscope adapter (USB

Instruments) that measured current across a reference resistor for a range of frequencies.

Impendence, defined as $\mathrm{Z}=\mathrm{V} / \mathrm{I}$, was measured at $15-\mathrm{Hz}$, where capacitance of the electrodes dominates and 15.6-kHz, where resistance of the culture media dominates29; the difference between these two values yielded the TEER measurement. These values were normalized using the impedance of an acellular hydrogel within the microfluidic device. 


\section{CD44 knockdown and upregulation}

Commercially available CRISPR plasmids (Santa Cruz) were used to alter the expression of CD44 within the HCMEC/D3 cells prior to introduction into the 3D BBB model. To knockout CD44 in the cells, two plasmids encoding a D10A mutated Cas9 nuclease and a CD44-specific 20 nucleotide guide RNA were transfected into cells (sc-400209-NIC). The paired guide RNA sequences were offset by approximately 20 basepairs to facilitate Cas9-mediated double nicking of genomic DNA. For scrambled controls, a single plasmid encoding a non-specific guide RNA sequence was transfected into cells (sc-418922). For the upregulation condition, lentiviral activation particles containing a SAM complex were delivered to cells to activate transcription of CD44 (sc-400209-LAC). Protocols for these assays were adapted from instructions provided by Santa Cruz. Briefly, cells were plated in a six well plate and grown to 60-70\% confluency. For HCAM activation, the cells were incubated with complete media containing $10 \mu \mathrm{g} / \mathrm{mL}$ polybrene prior to adding lentiviral particles at an MOI of 2. After 2 days, stable colonies were selected by incubation with $5 \mu \mathrm{g} / \mathrm{mL}$ puromycin in EGM-2. Cells were transfected with $\mathrm{KO}$ and control plasmids resuspended in nuclease free water at $0.1 \mu \mathrm{g} / \mu \mathrm{L}$. Both solutions were incubated for 5 minutes at room temperature. Following incubation, solutions were mixed, vortexed, and incubated for 20 minutes at room temperature. $300 \mu \mathrm{L}$ of the plasmid complex in $3 \mathrm{~mL}$ of culture medium was then added to each well. Media was replaced after 48 hours with complete EGM-2. Transfection efficiency was verified by western blotting: cells were lysed in sample buffer containing DTT and LDS, boiled, and loaded onto a gel and separated with electrophoresis. Proteins were transferred to a $0.45-\mu \mathrm{m}$ PVDF membrane. Blots were quantified by measuring band intensity using ImageJ and normalizing relative expression to control conditions. 
Membranes were incubated with anti-CD44(1:50) or anti-Beta actin(1:400) and visualized with HRP-conjugated secondary antibodies.

\section{Adducin- $\gamma$ knockdown}

DsiRNA directed against adducin- $\gamma$ (ADD3)30 was used to knock down protein expression in HCMEC/d3 cells (IDBT). Cells were plated in a 6-well plate at 250k per well. When cells reached 60-70\% confluency, DsiRNA was added as follows. Protocols were adapted from IDBT. Briefly, DsiRNA and negative control DsiRNA were resuspended in nuclease free water at 100 $\mu \mathrm{M}$. The stock solutions were diluted to $5 \mu \mathrm{M}$ working solution consisting of $5 \mathrm{x}$ siRNA buffer and nuclease free water. The working solution was diluted with transfection media to a $250 \mathrm{nM}$ concentration and incubated for 5 minutes at room temperature. Concurrently, Dharmafect was mixed with transfection medium and incubated for 5 minutes at room temperature. The solutions were mixed and incubated for another 5 minutes prior to adding the complex to complete EGM-2 to yield a final DsiRNA concentration of $25 \mathrm{nM}$. $2 \mathrm{~mL}$ was added per well of cells and incubated for 24 hours before replacing with complete EGM-2. DsiRNA-mediated knockdown efficiency was verified using western blotting. Cells cultured in a well plate for five days following plating were lysed for the western blots, since this period matched the timing of permeability testing.

\section{RhoA activation and inactivation}

In order to constitutively activate RhoA vessels at day 4 were perfused with Rho Activator II (Cytoskeleton) at a concentration of $2 \mu \mathrm{g} / \mathrm{mL}$ for four hours prior to use in permeability tests or fixation for immunocytochemistry. In order to assess the effects of RhoA inactivation, vessels were perfused with Rho Inhibitor I (Cytoskeleton) at a concentration of $2 \mu \mathrm{g} / \mathrm{mL}$ for four hours prior to use in permeability tests or immunocytochemistry.

\section{ELISA-based quantification of small GTPase activity}


Commercial ELISA kits were purchased from Cytoskeleton (G-LISA) to quantify RhoA and Rac1 activation (Cytoskeleton). For both cases, cell lysates were prepared using Cytoskeleton's protocols. Following exposure to flow or static conditions, the collagen/hyaluronan hydrogel was removed from the device and washed in ice cold 1x PBS for 30 seconds. $50 \mu \mathrm{L}$ of ice-cold cell lysis buffer with 1x protease inhibitor was injected into vessels and collected in a microcentrifuge tube. The cell lysate solution was spun at $10,000 \mathrm{~g}$ for 1 minute at $4{ }_{\circ} \mathrm{C}$ to pellet cell debris. The supernatant was collected and snap frozen in liquid nitrogen, reserving a small amount for protein quantification using Precision Red (Cytoskeleton). Prior to measuring GTPase activity, samples were thawed in a room temperature water bath and equilibrated to 1 $\mathrm{mg} / \mathrm{mL}$ for RhoA and $0.5 \mathrm{mg} / \mathrm{mL}$ for Rac1 samples.

\section{Activated RhoA immunoprecipitation}

Activated RhoA pulldown kits were purchased from Cytoskeleton. Sample lysates were prepared similar to the protocol used for G-LISAs. Samples were processed using Rhotekin-conjugated beads provided in the kit. $200 \mu \mathrm{g}$ of protein was incubated with $15 \mu \mathrm{L}$ of the beads, with $50 \mu \mathrm{g}$ reserved for quantifying total RhoA present in the sample. Following pulldown, samples were denatured in Lamelli buffer and separated using electrophoresis. $10 \mu \mathrm{L}$ of each sample was loaded per well on a 4-12\% tris glycine gel in MOPS buffer. The gel was transferred onto a 0.2$\mu \mathrm{m}$ PVDF membrane. Following transfer, the membrane was probed using the iBind flex kit and a primary anti-RhoA antibody (Cytoskeleton) at 1:200 and HRP-conjugated secondary (1:4000). Blots were quantified by measuring band intensity with ImageJ and normalizing relative expression to control conditions.

\section{ZO-1 immunoprecipitation}


Immunoprecipitation of ZO-1 was performed using cell lysates extracted from cell monolayers cultured on the collagen/HA hydrogels exposed to $24 \mathrm{hrs}$ of fluid shear stress applied by a cone and plate rheometer. The gels were removed from the rheometer and washed immediately in ice cold PBS. The gels were then submerged in ice cold lysis buffer (CST) and sonicated. Gels were then spun down at $14,000 \mathrm{~g}$ for 10 minutes at $4 \mathrm{oC}$. Supernatants were removed and snap frozen reserving a small aliquot for protein quantification. Samples were equilibrated at $0.5 \mathrm{mg} / \mathrm{mL}$ protein concentration using ice cold lysis buffer after thawing in a room temperature water bath. Samples were then loaded on a tris-acetate gel and separated using electrophoresis in tris-acetate buffer. Protein was transferred to a $0.45-\mu \mathrm{m}$ PVDF membrane. The membrane was incubated overnight with ZO-1(CST) (1:2000), ADD3 (Abcam)(1:400), or Spectrin- $\alpha$ II (ABcam)(1:1000) antibodies and visualized with HRP-conjugated secondary antibodies (1:4000).

\section{Statistical Analysis}

The open source statistics package, $\mathrm{R}$, was used to perform all statistical calculations. Data sets were tested for normality with Shapiro-Wilk tests prior to testing for significance. One and twoway ANOVA tests followed by Tukey HSD post-hoc comparisons were used to evaluate significant differences between multiple conditions. Paired t-tests were used to compare fold change of ADD3/ZO1 and Spectrin/ZO1 with shear stress in the immunoprecipitation experiments. All other two sample comparisons were made using Student's t-tests. Each statistical test used sample numbers greater than or equal to 3 unless otherwise noted and $\mathrm{p}<$ 0.05 was considered significant. All error bars indicate standard deviation of the mean.

\section{Results}

Fluid shear stress affects tight junctions and barrier integrity 
In order to gain a more complete understanding of the effect of shear stress on barrier function, a range of shear stress levels was applied to the 3D BBB model for a period of four days. Four different levels of shear stress (static control, $0.18,0.35$, and $0.7 \mathrm{dyn} / \mathrm{cm} 2$ ) were exerted by altering the volumetric flow rate of culture medium perfusing through the $3 \mathrm{D}$ vessels, which are depicted in Figure 1A. These magnitudes were chosen to represent the lower end of the shear stress range present in the brain vasculature 31

, which previous measurements have shown is substantially heterogeneous32, 33. Each vessel was submerged in culture medium during these experiments to assure equal access to nutrients and oxygen regardless of perfusion rate. Three separate assays evaluated barrier integrity: immunocytochemistry, FITC-dextran permeability assays, and transendothelial electrical resistance (TEER) measurements. The former two assays were conducted at the end of the perfusion period, but TEER measurements could be performed daily without disrupting the vessels. Fig 1B-E show the effect of varying magnitudes of fluid shear stress on the morphology of the endothelial cells lining the in vitro vessel and localization of ZO-1, a tight-junction associated scaffolding protein34. After 4 days in culture, static vessels (Fig. 1B) exhibited a substantial amount of perinuclear ZO-1 staining, with irregular localization to the junctions. Vessels exposed to low levels of shear stress ( 0.18 and 0.35 dyne/cm2 $)$ had a similar response, as evidenced in Figures 1C and 1D, respectively. In contrast, the vessel exposed to $0.7 \mathrm{dyn} / \mathrm{cm} 2$, indicated clear localization of ZO-1 to the cell-cell junctions without any gaps in the endothelial monolayer (Fig. 1E).

The permeability measurements quantitatively validated the observations yielded by immunocytochemistry. Figure $1 \mathrm{~F}$ indicates that only the vessels exposed to $0.7 \mathrm{dyn} / \mathrm{cm} 2 \mathrm{shear}$ stress resulted in a significantly lower permeability compared to lower shear stress magnitudes 
and the static control. Similarly, the TEER measurements found a significant increase in barrier integrity only in vessels exposed to $0.7 \mathrm{dyn} / \mathrm{cm}_{2}$ at days 3 and 4 following seeding of the cells within the hydrogel (Fig. 1G). TEER was also used to evaluate whether the presence of astrocytes in the surrounding hydrogel were required for barrier formation. Supplemental Figure 1A-B indicates no significant difference in FITC-dextran permeability and TEER values in hydrogels containing astrocytes. These findings further emphasize the importance of fluid shear stress in barrier regulation in cerebral vasculature.

\section{Hyaluronan mediates formation of the endothelial barrier}

Another means of interrogating the effect of shear stress on barrier function involves evaluating the dynamics of endothelial tight junctions after ceasing perfusion. These experiments also have clinical relevance due to the occlusion of cerebral blood flow during ischemic stroke. Vessels were exposed to $0.7 \mathrm{dyn} / \mathrm{cm}_{2}$ for four days prior to stopping flow (at time $=0$ ) and evaluating permeability at 20,60, 120, and 240 minutes. As Figure $2 \mathrm{~A}$ indicates, the permeability of the 3D vessels significantly increased at the 120 and 240-minute timepoints following removal from flow. These experiments were also conducted in the absence of hyaluronan (HA), to determine the importance of matrix formulation on flow-mediated barrier integrity. As Figures $2 \mathrm{~A}$ and $2 \mathrm{~B}$ show, vessels fabricated in collagen-only hydrogels exhibited a significantly higher permeability at the time when flow stopped, and there was no significant change in permeability in the four hours that followed. These results suggested that the presence of HA contributed to flowmediated barrier formation and maintenance.

Because CD44 is one of the main transmembrane receptors for HA, experiments were conducted to determine whether the receptor was involved in mechanotransduction of fluid shear stress in the cerebral endothelial cells. First, immunocytochemistry was performed on vessels patterned in 
both collagen/HA and collagen only scaffolds and exposed to four days of $0.7 \mathrm{dyn} / \mathrm{cm} 2 \mathrm{shear}$ stress. Figures 2C-D provide images of these vessels, and show that CD44 localizes to the cellcell junctions in vessels patterned in collagen/HA scaffolds, whereas the receptor is more diffuse throughout the cytoplasm and does not localize strongly to cell-cell junctions in the collagen only hydrogels. Side views of the vessels in collagen only hydrogels reveal CD44 localized to the apical sides of the endothelium where there is likely a robust glycocalyx layer (Fig. 2Ciii), though positive staining is observed in both apical and basal sides in collagen/HA hydrogels, suggesting that binding of the receptor to the extracellular matrix is crucial for the observed flow response (Fig 2Diii).

\section{CD44 mediates barrier formation in response to shear stress}

In order to further interrogate the role of CD44 in flow mechanotransduction, HCMEC/D3 cells were genetically modified using the CRISPR/Cas9 system to both knockout and upregulate the expression of the receptor. A CRISPR/Cas9 plasmid containing a scrambled guide sequence was used as a control for these experiments. Double nickase plasmids were used to knockout CD4435, and the SAM activation system was used to constitutively increase expression36. Western blotting validated the effect of gene editing on CD44 expression (Figs. 3A-B). Having measured CD44 expression levels, four separate conditions were evaluated using immunocytochemistry, FITC-dextran permeability tests, and TEER measurements: (i) scrambled control cells in collagen/HA hydrogels exposed to flow, (ii) CD44-upregulated cells in collagen only hydrogels exposed to flow, (iii) CD44-upregulated in collagen/HA hydrogels in static culture, and (iv) CD44 knockout cells in collagen/HA hydrogels exposed to flow. The purpose of these conditions was to determine whether CD44 was necessary for flow-mediated barrier formation and whether increasing the expression of CD44 could recover barrier function in the absence of HA or flow. 
Immunocytochemistry provided insight into the morphology and expression of tight junctions; Figures 3C-F provide composites of DAPI and GFP with ZO-1 (i) as well as isolated ZO-1 images (ii). Vessels treated with scrambled guide sequences were not affected by transfection , ZO-1 is observed at the cell-cell junctions with minimal perinuclear localization (Fig. 3C). The transformed cells did not exhibit different barrier integrity compared to normal cells determined by permeability and TEER measurements (Supplementary Figure 2). Upregulation of CD44 in static collagen/HA hydrogels was not able to recover barrier formation observed in the presence of flow, as evidenced by a disrupted monolayer and diffuse ZO-1 staining (Fig. 3D). Similarly, constitutive activation of CD44 in collagen scaffolds exposed to flow exhibited limited ZO-1 localization to the cell-cell junctions (Fig. 3E), demonstrating that expression of CD44 in the absence of HA could not recover function. Finally, CD44 knockout cells in collagen/HA scaffolds exposed to flow resulted in discontinuous localization of ZO-1 to the cell-cell junctions and gaps within the monolayer (Fig. 3F). FITC-dextran permeability assays (Fig. 3G) and daily TEER measurements (Fig. 3H) confirm these immunocytochemistry observations. In both assays, the scrambled control had significantly higher barrier function compared to the other conditions. Overall, these results suggest that all three elements: ZO-1 expression, HA in the extracellular matrix, and shear stress are required for flow-mediated barrier formation.

\section{Small GTPases regulate barrier integrity}

Given that previous studies have found CD44 activation affects small GTPases associated with cell mechanotransduction37, studies were conducted to determine the effect of shear stress on RhoA and Rac1 activation within the 3D BBB model. Although the effect of RhoA activation on the blood-brain barrier has been extensively studied8, 16,21, 38-41, its response to fluid shear stress in cerebral endothelial cells has yet to be studied. Here, vessels were treated with a Rho 
inhibitor prior for four hours prior to stopping flow or treated with a Rho activator in the last four hours of the four-day perfusion. Immunocytochemistry shows that modulating RhoA activation has a substantial effect on the morphology of the endothelial cells. Figure 4A shows strong ZO-1 localization to the junction following 240 minutes of no flow. Additionally, the membrane protein adducin- $\boldsymbol{\gamma}$ was also localized to the junction in this condition (Fig. 4A, iii). In contrast, exposure to the Rho activator resulted in barrier disruption and more perinuclear staining of the ZO-1 (Fig. 4B). FITC-dextran permeability testing with vessels perfused with the Rho inhibitor exhibited no significant increase in permeability, as shown in Figure 4C. Additionally, the permeability at the end of the four-day perfusion was significantly higher in vessels treated with the Rho activator (Fig. 4D).

ELISAs and immunoprecipitation assays provided further insight into the effect of flow on the activation of small GTPases. Due to the amount of protein required for these assays, the 3D BBB model was altered for these experiments. A larger diameter vessel (1-mm), which has been previously used for high Reynolds number studies26, was endotheliaized and exposed to 2.1 $\mathrm{dyn} / \mathrm{cm} 2$ of shear stress. Figure 5 shows that application of $2.1 \mathrm{dyn} / \mathrm{cm} 2$ significantly reduced the level of RhoA activity, as measured by the Rhotekin-pulldown (Fig. 5A) and ELISA (Fig. 5B) assays. Both assays indicated a reduction of nearly 50\% compared to static controls. An ELISA was also conducted for Rac1, and found that Rac1 activation was significantly increased at the 6$\mathrm{hr}$ and 24-hr time points following the start of perfusion. These assays indicate that flow results in differential expression of RhoA and Rac1: shear stress significantly decreases RhoA activation while significantly increasing Rac1 activation.

\section{Adducin- $\gamma$ localization is a downstream effect of Rac1 activation.}


Given that adducin- $\gamma$ localized to the junctions in vessels exposed to the Rho inhibitor, experiments were conducted to determine the importance of this membrane protein to flowmediated barrier formation. In order to determine whether adducin- $\gamma$ expression was necessary for barrier integrity, siRNA was used to knockdown levels of adducin- $\gamma$ in the HCMEC/D3 cells (Figs. 6A-B). Knockdown efficiency was measured 5 days after transfection to ensure that in vitro vessels seeded with treated endothelial cells would express reduced levels of adducin- $\gamma$ during the perfusion period. Permeability testing of vessels containing the knockdown cells exhibited significantly higher permeability compared to scrambled controls (Fig. 6C). As Figures 6D-E indicate, the localization of adducin- $\gamma$ to the junctions was significantly different in vessels exposed to $0.7 \mathrm{dyn} / \mathrm{cm} 2$ shear stress compared to static controls. In order to determine whether a tight junction-associated complex incorporating adducin- $\gamma$ formed in response to flow, ZO-1 immunoprecipitations were performed. Similar to the ELISAs used to evaluate small GTPase activity, a substantial amount of protein was also required for these experiments. Therefore, HCMEC/D3 cells were seeded on the surface of collagen/HA hydrogels and placed in a cone and plate rheometer to apply a steady shear stress of 0.7 or $2.1 \mathrm{dyn} / \mathrm{cm} 2$. Immunocytochemistry verified that the monolayer exhibited a difference in ZO-1 localization in response to shear stress (Supplementary Figure 3), indicating that cells seeded on flat gels responded similarly to cells seeded within a 3D vessel. As Figures 6F-G show, the application of shear stress resulted in significantly higher levels of adducin- $\gamma$ in the ZO-1 pulldown compared to static controls. Significantly increased levels of spectrin- $\alpha$ II bound to the ZO-1 complex were also measured in response to shear (Supplementary Figure 4), consistent with previous findings that spectrin binds to adducin42. Overall, these results indicate that adducin- $\gamma$ localization is an integral downstream result of flow-mediated CD44 activation and differential activation of Rac1 and RhoA. 


\section{Discussion}

Our results identify a previously unreported signaling transduction mechanism that mediates blood-brain barrier formation in response to fluid shear stress. Figure 7 summarizes the components of this pathway. CD44 acts a mechanosensory and localizes to junctions in response to shear stress, activating Rac1 while inhibiting RhoA, which induces a complex including ZO-1, adducin- $\gamma$, and spectrin- $\alpha$ II at the cell-cell junctions. Our findings suggest that a requisite level of shear stress is needed to activate this pathway, given that levels of shear stress less than 0.7 $\mathrm{dyn} / \mathrm{cm} 2$ were unable to significantly increase barrier formation and maintenance during perfusion. Moreover, CRISPR-mediated alteration to CD44 levels suggest that all three components: hyaluronan, CD44, and shear stress all bolster barrier integrity in the in vitro 3D BBB model used. Our study concludes that this CD44-mediated mechanism is integral to bloodbrain barrier mechanotransduction, identifying an alternative mechanosensors of shear stress14.

The role of CD44 in mechanotransduction has been well-studied43, but its importance for sensing shear stress has yet to be investigated in detail. A previous study using bovine aortic endothelial cells found that inhibiting hyaluronan synthesis negated flow-mediated cell spreading on soft (100 Pa) two-dimensional substrates44, suggesting that CD44 may mediate acto-myosin contractility in the presence of shear stress. Here, the importance of CD44 was initially revealed due to the difference between vessels fabricated in collagen-only and collagen/HA hydrogels. There was a significantly lower permeability in collagen/HA hydrogels where CD44 is present on both apical and basal sides, compared to collagen-only hydrogels where CD44 is only present on the apical side, likely due to the presence of the glycocalyx. Previous studies have demonstrated the importance of the glycocalyx in flow mechanotransduction, and vessels fabricated in collagen-only hydrogels still have a significantly lower permeability than static 
controls after perfusion. Yet, our results demonstrate that the presence of HA in the ECM yields a significantly lower permeability, suggesting that cell-matrix adhesions are important for mediating the flow response.

ELISA and pulldown studies indicated that shear stress also significantly increased the activation of Rac1 while attenuating the activation of RhoA, demonstrating that the activity of these small GTPases is affected by shear stress. The activation of RhoA has been shown to induce cell contractility and cytoskeleton restructuring, resulting in enhanced cell motility and disrupted barrier integrity20,21,45. Conversely, Rac1 has been identified as a key mediator of vascular integrity in systemic vasculature12,15. Previous studies have shown that CD44 can activate these small GTPases37, 46, but the results presented here find that this interaction is important in mechanosensing. It is possible that CD44 may differentially regulate RhoA and Rac1 depending upon both mechanical and biochemical factors. A recent study found that the presence of small fragments of HA $(<4-8 \mathrm{kDa})$ resulted in CD44-mediated barrier breakdown47, suggesting that the molecular weight of HA may modulate the CD44 response. Overall, these results suggest that the effect of CD44 on downstream small GTPases can be altered by multiple factors.

Another crucial component of the signaling mechanism involves adducin- $\gamma$ localization to tight junctions in the presence of shear stress. Adducin- $\gamma$ has been shown in previous work to stabilize cell-cell junctions 48 and is a ROCK substrate 42,49 . Studies have found that adducin- $\gamma$ is an important component of both adherens and tight junctions within endothelial cells, and that it mediates cAMP signaling50. Additionally, the increase in spectrin- $\alpha$ II bound to the tight junction complex in response to flow indicates a potential role in stabilization of the tight-junction complex. Previously studies have identified the ankyrin-adducin-spectrin complex, which binds 
to transmembrane proteins bridging the gap to the cytoskeleton51. Specifically, spectrin- $\alpha$ II is associated with the brain and its cleavage products are a potential biomarker for neurodegenerative disorders52. These findings indicate that that the association of adducin- $\gamma$ and spectrin- $\alpha$ II may contribute to barrier function, yet additional studies are required to determine how the activity of RhoA and Rac1 affects the localization of these proteins in cell-cell junctions. Nonetheless, the knockdown studies suggest that adducin- $\gamma$ is required to maintain blood-brain barrier integrity, since reducing its expression resulted in increased permeability and barrier disruption. Clinical studies have identified adducin- $\gamma$ as a factor that can contribute to altered cerebral vascular function53, providing further evidence of its importance in maintenance of the blood-brain barrier.

Taken together, these results demonstrate a new mechanism by which fluid shear stress is transduced by endothelial cells within the blood-brain barrier. These findings point to new directions for therapeutic treatments to attenuate blood-brain barrier leakage during the "noreflow" period following cerebral ischemia-reperfusion injury when attenuation of cerebral blood flow correlates with increased barrier breakdown and other pathologies associated with vascular degradation in the central nervous system3. Future work is required to investigate crosstalk between this pathway and previously studied mechanosensitive mediators of vascular integrity6, $11,12,54$, and to determine ways in which this mechanism can be manipulated in vivo. Overall, the proposed mechanism not only provides targets for new therapeutic approaches, but also contributes to a mechanistic understanding of blood-brain barrier formation, specifically in response to fluid shear stress.

\section{Acknowledgments}


This work was supported by an American Heart Asssociation Scientist Development Grant

awarded to P.A.G. (17SDG33460432), National Institute of Health grant awarded to F.F

(RO1AG057842). and National Science Foundation GRFP fellowship awarded to B.J.D.

\section{Disclosures}

The authors have no conflict of interest to disclose

\section{References}

1. Cucullo L, Hossain M, Puvenna V, Marchi N, Janigro D. The role of shear stress in blood-brain barrier endothelial physiology. BMC Neurosci. 2011;12:40

2. Partyka PP, Godsey GA, Galie JR, Kosciuk MC, Acharya NK, Nagele RG, Galie PA. Mechanical stress regulates transport in a compliant $3 \mathrm{~d}$ model of the blood-brain barrier. Biomaterials. 2017;115:30-39

3. Kloner RA, King KS, Harrington MG. No-reflow phenomenon in the heart and brain. Am J Physiol Heart Circ Physiol. 2018;315:H550-H562

4. Knowland D, Arac A, Sekiguchi KJ, Hsu M, Lutz SE, Perrino J, Steinberg GK, Barres BA, Nimmerjahn A, Agalliu D. Stepwise recruitment of transcellular and paracellular pathways underlies blood-brain barrier breakdown in stroke. Neuron. 2014;82:603-617

5. Sandoval KE, Witt KA. Blood-brain barrier tight junction permeability and ischemic stroke. Neurobiol Dis. 2008;32:200-219

6. Dorland YL, Huveneers S. Cell-cell junctional mechanotransduction in endothelial remodeling. Cell Mol Life Sci. 2017;74:279-292

7. Li YS, Haga JH, Chien S. Molecular basis of the effects of shear stress on vascular endothelial cells. J Biomech. 2005;38:1949-1971

8. Radeva MY, Waschke J. Mind the gap: Mechanisms regulating the endothelial barrier. Acta Physiol (Oxf). 2018;222

9. Davies PF. Flow-mediated endothelial mechanotransduction. Physiol Rev. 1995;75:519560

10. Pahakis MY, Kosky JR, Dull RO, Tarbell JM. The role of endothelial glycocalyx components in mechanotransduction of fluid shear stress. Biochem Biophys Res Commun. 2007;355:228-233

11. Tzima E, Irani-Tehrani M, Kiosses WB, Dejana E, Schultz DA, Engelhardt B, Cao G, DeLisser H, Schwartz MA. A mechanosensory complex that mediates the endothelial cell response to fluid shear stress. Nature. 2005;437:426-431

12. Polacheck WJ, Kutys ML, Yang J, Eyckmans J, Wu Y, Vasavada H, Hirschi KK, Chen CS. A non-canonical notch complex regulates adherens junctions and vascular barrier function. Nature. 2017;552:258-262

13. Sherman LS, Struve JN, Rangwala R, Wallingford NM, Tuohy TM, Kuntz Ct. Hyaluronate-based extracellular matrix: Keeping glia in their place. Glia. 2002;38:93-102

14. Givens C, Tzima E. Endothelial mechanosignaling: Does one sensor fit all? Antioxid Redox Signal. 2016;25:373-388 
15. Waschke J, Baumgartner W, Adamson RH, Zeng M, Aktories K, Barth H, Wilde C, Curry FE, Drenckhahn D. Requirement of rac activity for maintenance of capillary endothelial barrier properties. Am J Physiol Heart Circ Physiol. 2004;286:H394-401

16. Stamatovic SM, Dimitrijevic OB, Keep RF, Andjelkovic AV. Protein kinase calpha-rhoa cross-talk in ccl2-induced alterations in brain endothelial permeability. J Biol Chem. 2006;281:8379-8388

17. Stamatovic SM, Keep RF, Kunkel SL, Andjelkovic AV. Potential role of mcp-1 in endothelial cell tight junction 'opening': Signaling via rho and rho kinase. J Cell Sci. 2003;116:4615-4628

18. Zhao H, Zhang X, Dai Z, Feng Y, Li Q, Zhang JH, Liu X, Chen Y, Feng H. P2x7 receptor suppression preserves blood-brain barrier through inhibiting rhoa activation after experimental intracerebral hemorrhage in rats. Sci Rep. 2016;6:23286

19. Park JC, Baik SH, Han SH, Cho HJ, Choi H, Kim HJ, Choi H, Lee W, Kim DK, MookJung I. Annexin a1 restores abeta1-42 -induced blood-brain barrier disruption through the inhibition of rhoa-rock signaling pathway. Aging Cell. 2017;16:149-161

20. Kugelmann D, Rotkopf LT, Radeva MY, Garcia-Ponce A, Walter E, Waschke J. Histamine causes endothelial barrier disruption via ca(2+)-mediated rhoa activation and tension at adherens junctions. Sci Rep. 2018;8:13229

21. Mikelis CM, Simaan M, Ando K, Fukuhara S, Sakurai A, Amornphimoltham P, Masedunskas A, Weigert R, Chavakis T, Adams RH, Offermanns S, Mochizuki N, Zheng Y, Gutkind JS. Rhoa and rock mediate histamine-induced vascular leakage and anaphylactic shock. Nat Commun. 2015;6:6725

22. Wojciak-Stothard B, Ridley AJ. Rho gtpases and the regulation of endothelial permeability. Vascul Pharmacol. 2002;39:187-199

23. Wang ZG, Cheng Y, Yu XC, Ye LB, Xia QH, Johnson NR, Wei X, Chen DQ, Cao G, Fu XB, Li XK, Zhang HY, Xiao J. Bfgf protects against blood-brain barrier damage through junction protein regulation via pi3k-akt-rac1 pathway following traumatic brain injury. Mol Neurobiol. 2016;53:7298-7311

24. Weksler BB, Subileau EA, Perriere N, Charneau P, Holloway K, Leveque M, TricoireLeignel H, Nicotra A, Bourdoulous S, Turowski P, Male DK, Roux F, Greenwood J, Romero IA, Couraud PO. Blood-brain barrier-specific properties of a human adult brain endothelial cell line. FASEB J. 2005;19:1872-1874

25. Placone AL, McGuiggan PM, Bergles DE, Guerrero-Cazares H, Quinones-Hinojosa A, Searson PC. Human astrocytes develop physiological morphology and remain quiescent in a novel 3d matrix. Biomaterials. 2015;42:134-143

26. Bouhrira N, DeOre BJ, Sazer DW, Chiaradia Z, Miller JS, Galie PA. Disturbed flow disrupts the blood-brain barrier in a 3d bifurcation model. Biofabrication. 2019

27. Bowers HC, Fiori ML, Khadela JB, Janmey PA, Galie PA. Cell-matrix tension contributes to hypoxia in astrocyte-seeded viscoelastic hydrogels composed of collagen and hyaluronan. Exp Cell Res. 2019;376:49-57

28. Adamson RH, Lenz JF, Curry FE. Quantitative laser scanning confocal microscopy on single capillaries: Permeability measurement. Microcirculation. 1994;1:251-265

29. Benson K, Cramer S, Galla HJ. Impedance-based cell monitoring: Barrier properties and beyond. Fluids Barriers CNS. 2013;10:5 
30. Fan F, Pabbidi MR, Ge Y, Li L, Wang S, Mims PN, Roman RJ. Knockdown of add3 impairs the myogenic response of renal afferent arterioles and middle cerebral arteries. American journal of physiology. Renal physiology. 2017;312:F971-F981

31. Mairey E, Genovesio A, Donnadieu E, Bernard C, Jaubert F, Pinard E, Seylaz J, OlivoMarin JC, Nassif X, Dumenil G. Cerebral microcirculation shear stress levels determine neisseria meningitidis attachment sites along the blood-brain barrier. $J$ Exp Med. 2006;203:1939-1950

32. Villringer A, Them A, Lindauer U, Einhaupl K, Dirnagl U. Capillary perfusion of the rat brain cortex. An in vivo confocal microscopy study. Circ Res. 1994;75:55-62

33. Hudetz AG, Feher G, Knuese DE, Kampine JP. Erythrocyte flow heterogeneity in the cerebrocortical capillary network. Adv Exp Med Biol. 1994;345:633-642

34. Dejana E. Endothelial cell-cell junctions: Happy together. Nat Rev Mol Cell Biol. 2004;5:261-270

35. Ran FA, Hsu PD, Lin CY, Gootenberg JS, Konermann S, Trevino AE, Scott DA, Inoue A, Matoba S, Zhang Y, Zhang F. Double nicking by rna-guided crispr cas9 for enhanced genome editing specificity. Cell. 2013;154:1380-1389

36. Konermann S, Brigham MD, Trevino AE, Joung J, Abudayyeh OO, Barcena C, Hsu PD, Habib N, Gootenberg JS, Nishimasu H, Nureki O, Zhang F. Genome-scale transcriptional activation by an engineered crispr-cas9 complex. Nature. 2015;517:583-588

37. Bourguignon LY. Matrix hyaluronan-activated cd44 signaling promotes keratinocyte activities and improves abnormal epidermal functions. Am J Pathol. 2014;184:1912-1919

38. Sladojevic N, Yu B, Liao JK. Rock as a therapeutic target for ischemic stroke. Expert Rev Neurother. 2017;17:1167-1177

39. Lai AY, McLaurin J. Rho-associated protein kinases as therapeutic targets for both vascular and parenchymal pathologies in alzheimer's disease. J Neurochem. 2018;144:659-668

40. Ramirez SH, Heilman D, Morsey B, Potula R, Haorah J, Persidsky Y. Activation of peroxisome proliferator-activated receptor gamma (ppargamma) suppresses rho gtpases in human brain microvascular endothelial cells and inhibits adhesion and transendothelial migration of hiv-1 infected monocytes. J Immunol. 2008;180:1854-1865

41. Baumer Y, Burger S, Curry FE, Golenhofen N, Drenckhahn D, Waschke J. Differential role of rho gtpases in endothelial barrier regulation dependent on endothelial cell origin. Histochem Cell Biol. 2008;129:179-191

42. Matsuoka Y, Li X, Bennett V. Adducin: Structure, function and regulation. Cell Mol Life Sci. 2000;57:884-895

43. Razinia Z, Castagnino P, Xu T, Vazquez-Salgado A, Pure E, Assoian RK. Stiffnessdependent motility and proliferation uncoupled by deletion of cd44. Sci Rep. 2017;7:16499

44. Galie PA, van Oosten A, Chen CS, Janmey PA. Application of multiple levels of fluid shear stress to endothelial cells plated on polyacrylamide gels. Lab Chip. 2015;15:12051212

45. Shaw RJ, Henry M, Solomon F, Jacks T. Rhoa-dependent phosphorylation and relocalization of erm proteins into apical membrane/actin protrusions in fibroblasts. $\mathrm{Mol}$ Biol Cell. 1998;9:403-419

46. Bourguignon LY. Hyaluronan-mediated cd44 activation of rhogtpase signaling and cytoskeleton function promotes tumor progression. Semin Cancer Biol. 2008;18:251-259 
47. Al-Ahmad AJ, Patel R, Palecek SP, Shusta EV. Hyaluronan impairs the barrier integrity of brain microvascular endothelial cells through a cd44-dependent pathway. J Cereb Blood Flow Metab. 2019;39:1759-1775

48. Naydenov NG, Ivanov AI. Adducins regulate remodeling of apical junctions in human epithelial cells. Mol Biol Cell. 2010;21:3506-3517

49. Kugelmann D, Waschke J, Radeva MY. Adducin is involved in endothelial barrier stabilization. PLOS ONE. 2015;10:e0126213

50. Ponce AG, Radeva MY, Waschke J. A-adducin is crucial for endothelial tight junction integrity. The FASEB Journal. 2019;33:686.683-686.683

51. Baines AJ, Lu HC, Bennett PM. The protein 4.1 family: Hub proteins in animals for organizing membrane proteins. Biochim Biophys Acta. 2014;1838:605-619

52. Yan XX, Jeromin A, Jeromin A. Spectrin breakdown products (sbdps) as potential biomarkers for neurodegenerative diseases. Curr Transl Geriatr Exp Gerontol Rep. 2012;1:85-93

53. Shekhar S, Liu R, Travis OK, Roman RJ, Fan F. Cerebral autoregulation in hypertension and ischemic stroke: A mini review. J Pharm Sci Exp Pharmacol. 2017;2017:21-27

54. Hahn C, Schwartz MA. Mechanotransduction in vascular physiology and atherogenesis. Nat Rev Mol Cell Biol. 2009;10:53-62 


\section{Figures}
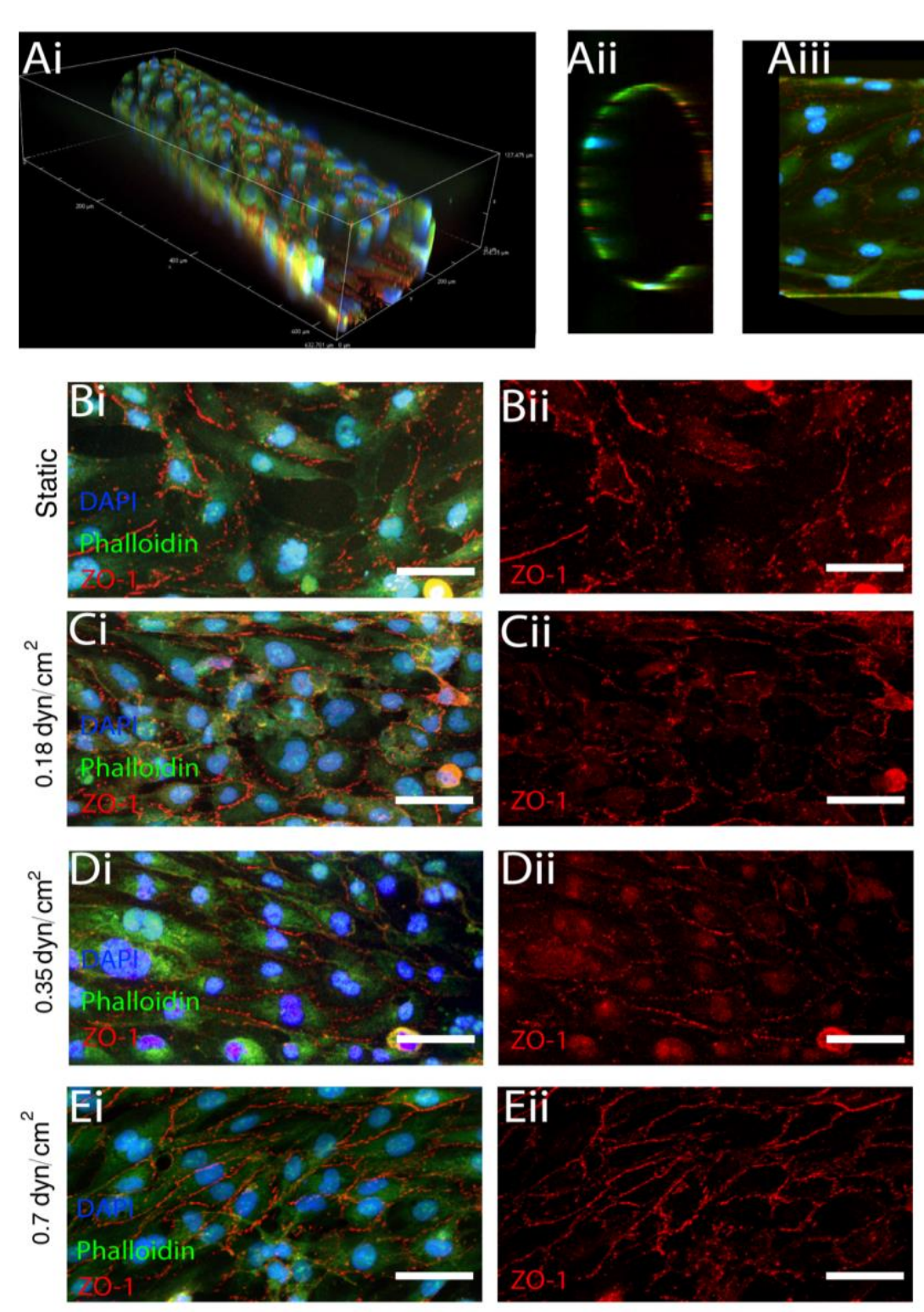
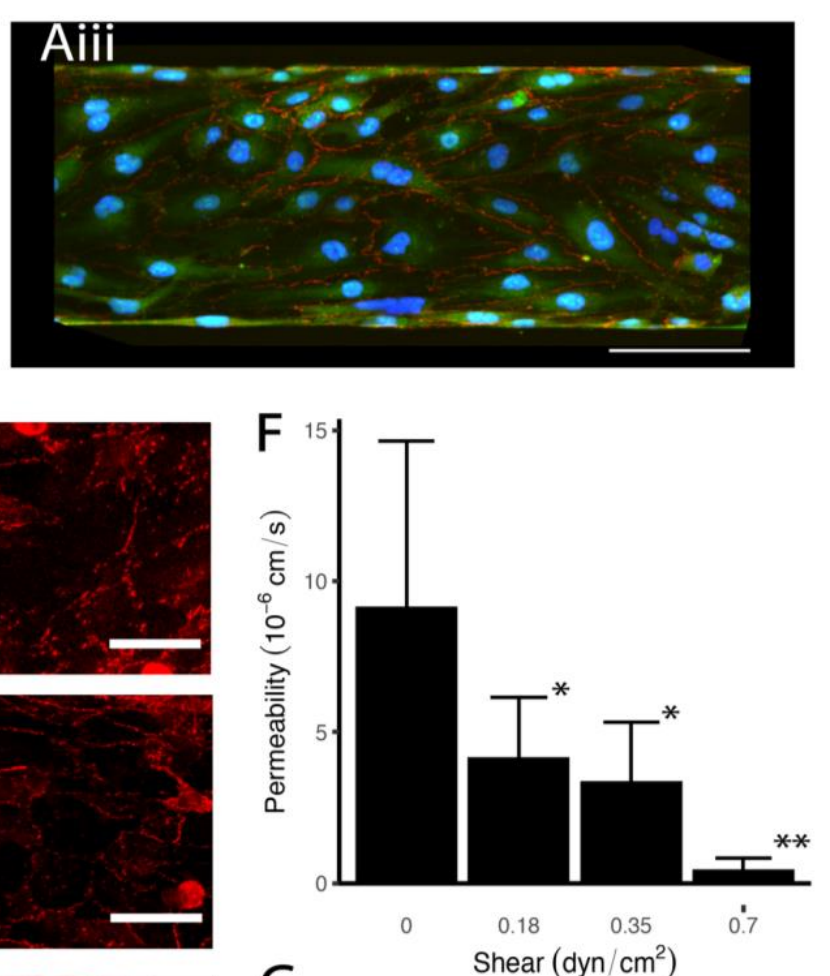

G

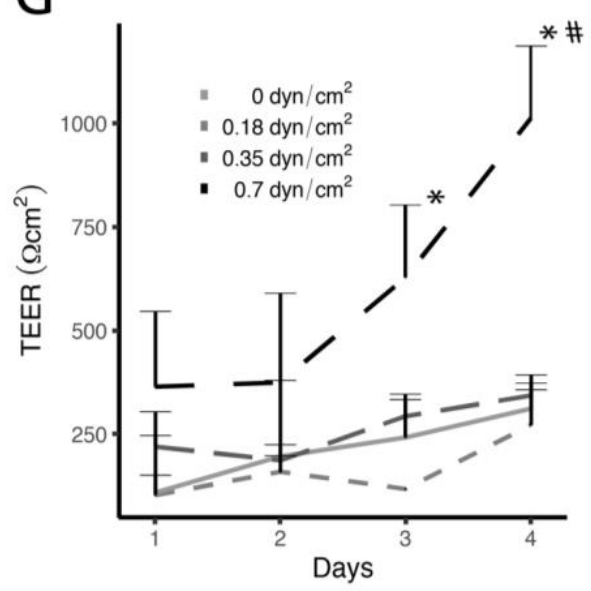

\section{Figure 1 Fluid Shear stress affects tight junctions and barrier integrity}

A Fluorescent images of HCMEC/D3-seeded channels cultured for 4 days in 3D (i), cross-section (ii), and maximum projection in the $\mathrm{x}$ and y plane(iii) scale $=100 \mu \mathrm{m}$. B Static, $\mathbf{C} 0.18 \mathrm{dyn} / \mathrm{cm} 2, \mathbf{D} 0.35$ $\mathrm{dyn} / \mathrm{cm}_{2}$, E $0.7 \mathrm{dyn} / \mathrm{cm}_{2}$ images showing DAPI (blue), phalloidin (green), and anti-ZO-1 (red) (isolated in ii) staining of the vessel wall. scale $=50 \mu \mathrm{m} \mathbf{F}$ Permeability coefficient of channels exposed to static or shear conditions for 4 days measured with $4 \mathrm{kDa}$ dextran, *denotes $\mathrm{p}<0.05$ and $* *$ denotes $\mathrm{p}<$ 0.001 compared to static condition. F TEER measurements for channels exposed to static or shear conditions for 4 days, *denotes $\mathrm{p}<0.05$ compared to Day 1 value for each condition. \# indicates $\mathrm{p}<0.05$ compared to Day 4 values for each condition 


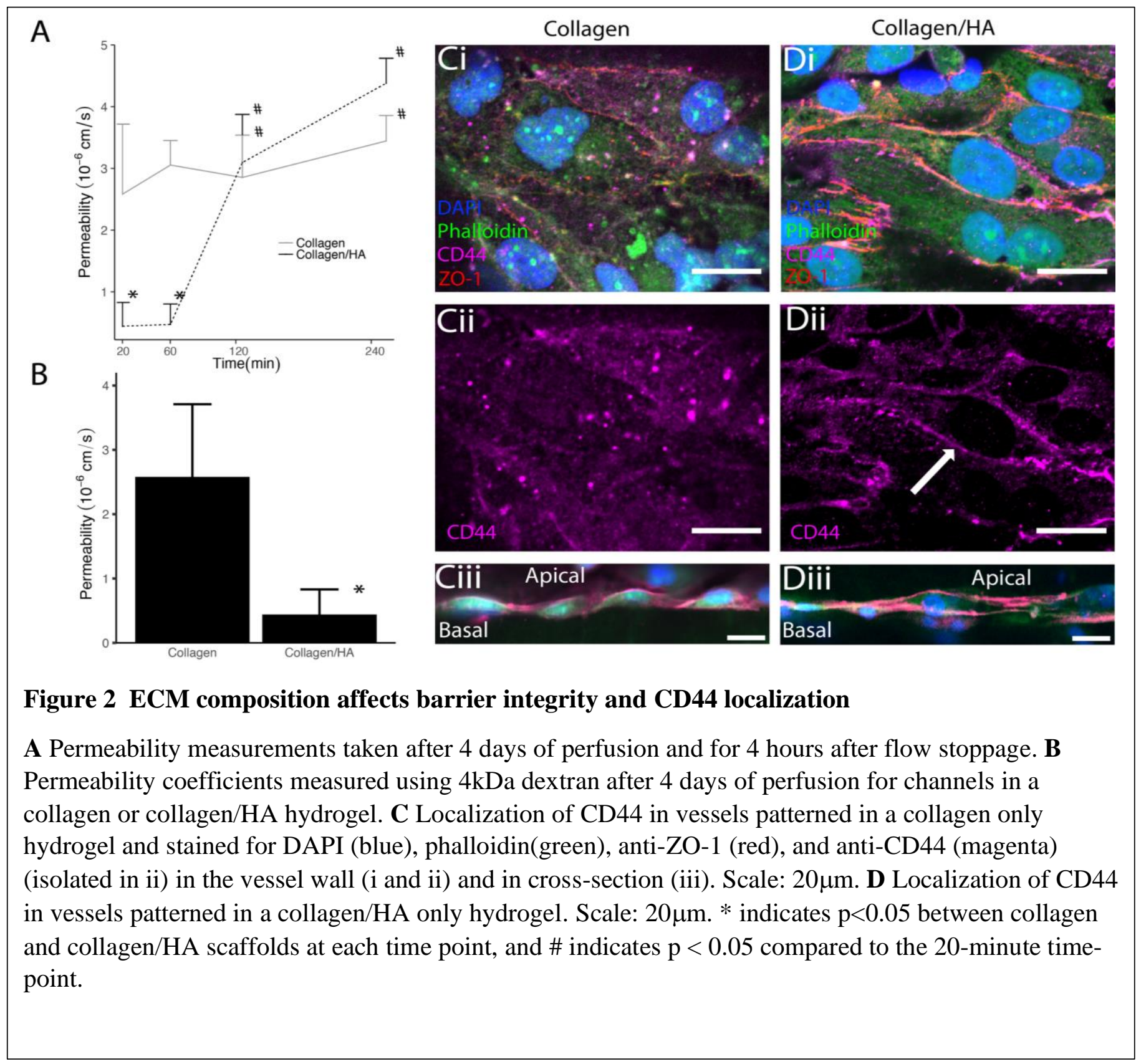




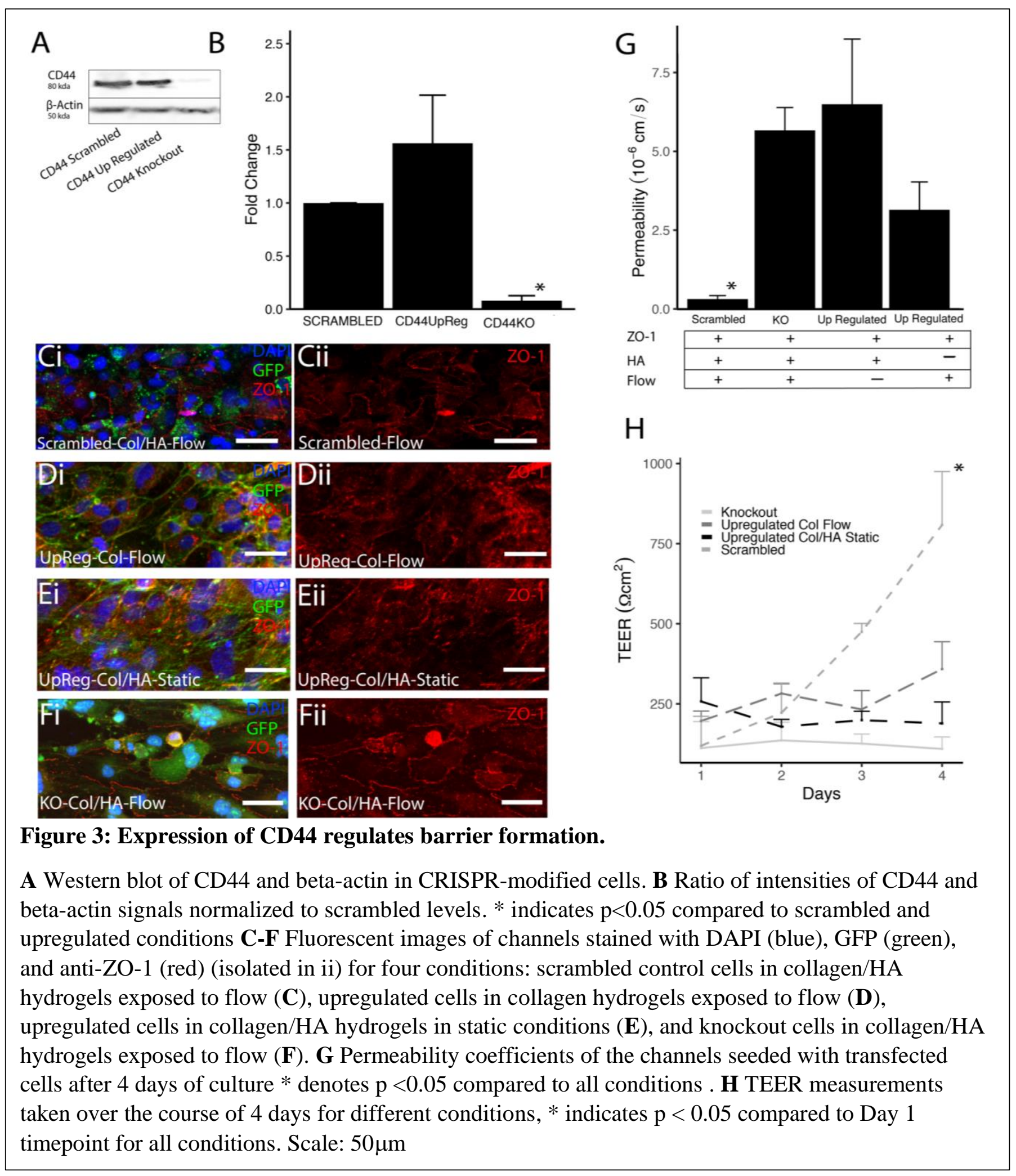




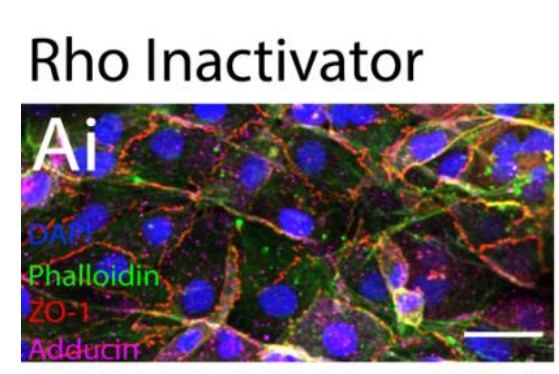

\section{Rho Activator}
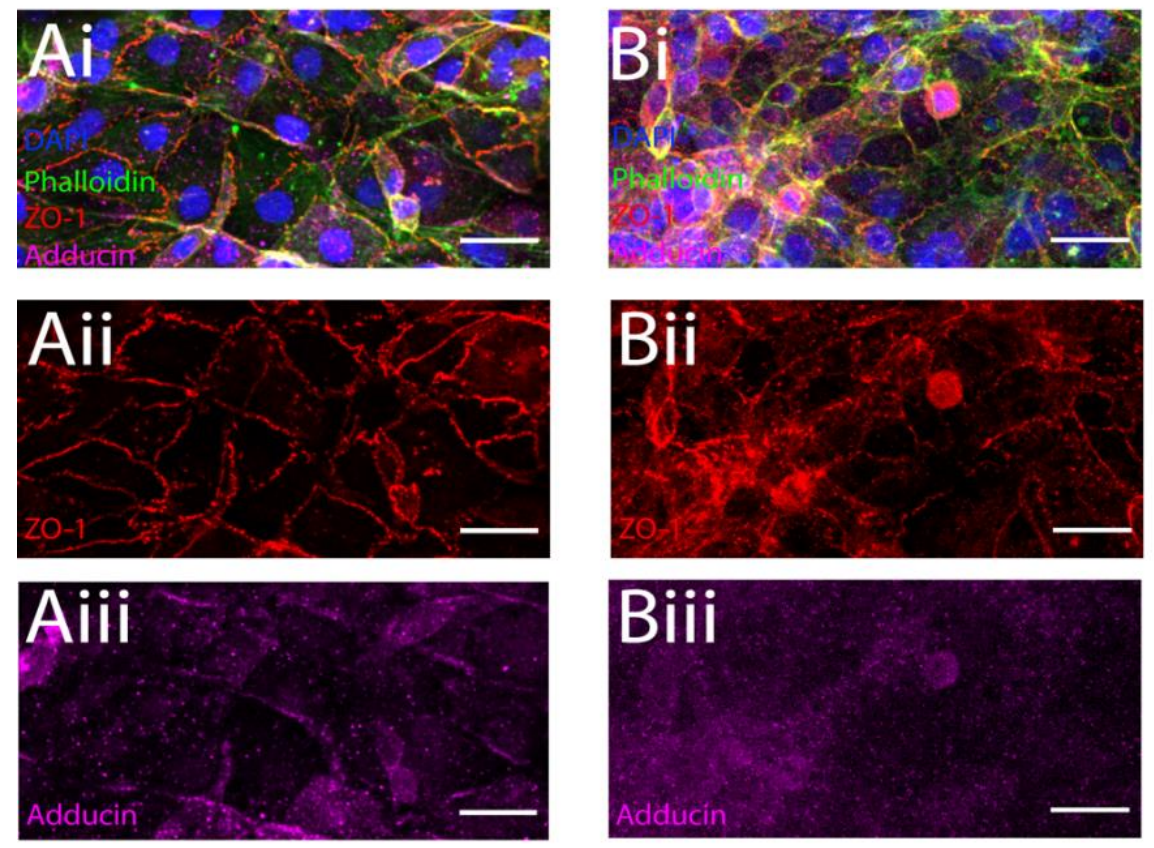
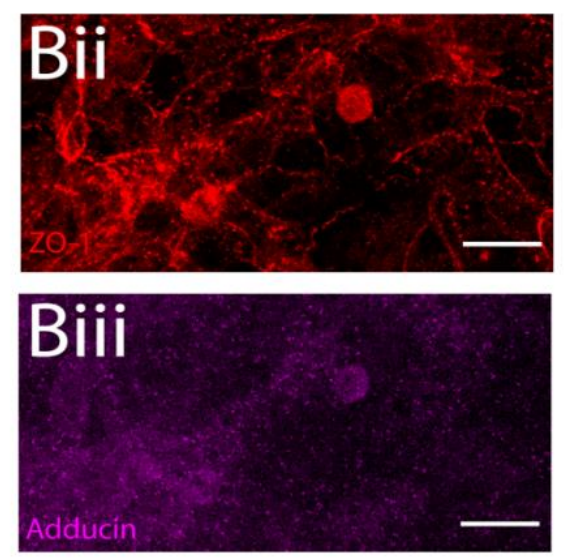
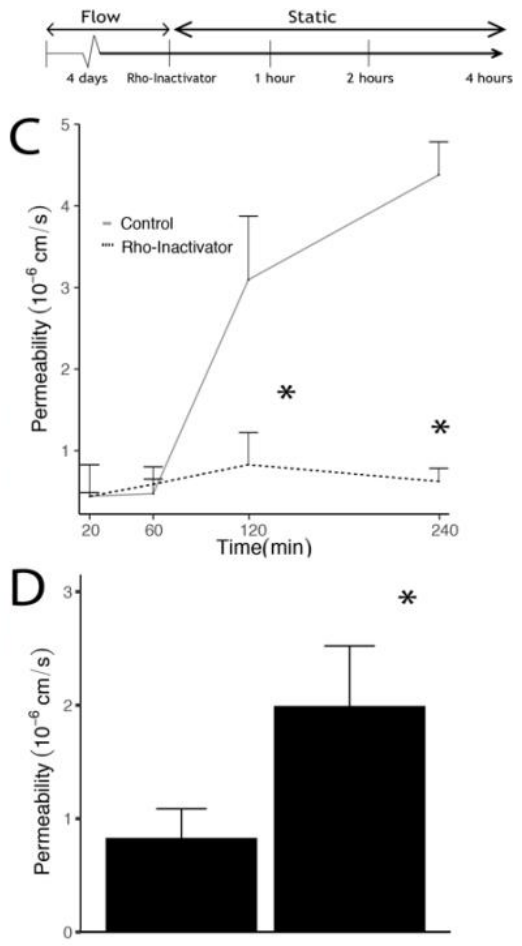

Control

\section{Figure 4: Fluid shear stress mediates Rac1 and RhoA activation.}

A-B Fluorescent images of vessels stained with DAPI (blue), ZO-1(red) (isolated in ii), and adducin (magenta) (isolated in iii) for Rho Inactivator (A) and Rho Activator (B). Scale: $50 \mu \mathrm{m}$ C Permeability coefficients of channels perfused for 4 days then incubated with a Rho inactivator for 4 hours prior to flow stoppage. * indicates $\mathrm{p}<0.05$ compared to the control condition for each time point. D Permeability coefficients of channels perfused for 4 days then exposed to a Rho Activator for 4 hours prior to measurement. * indicates $\mathrm{p}<0.05$. 


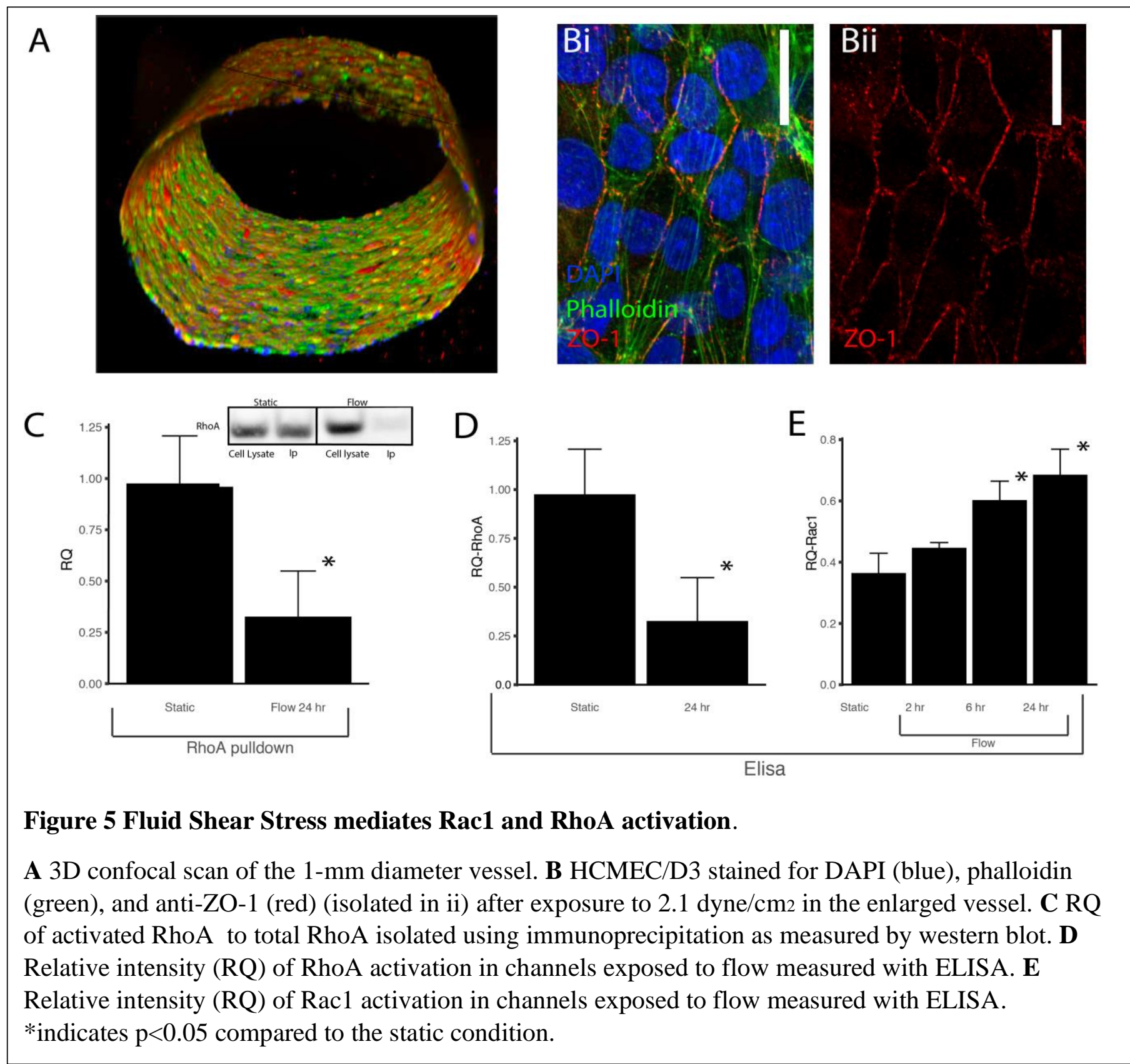




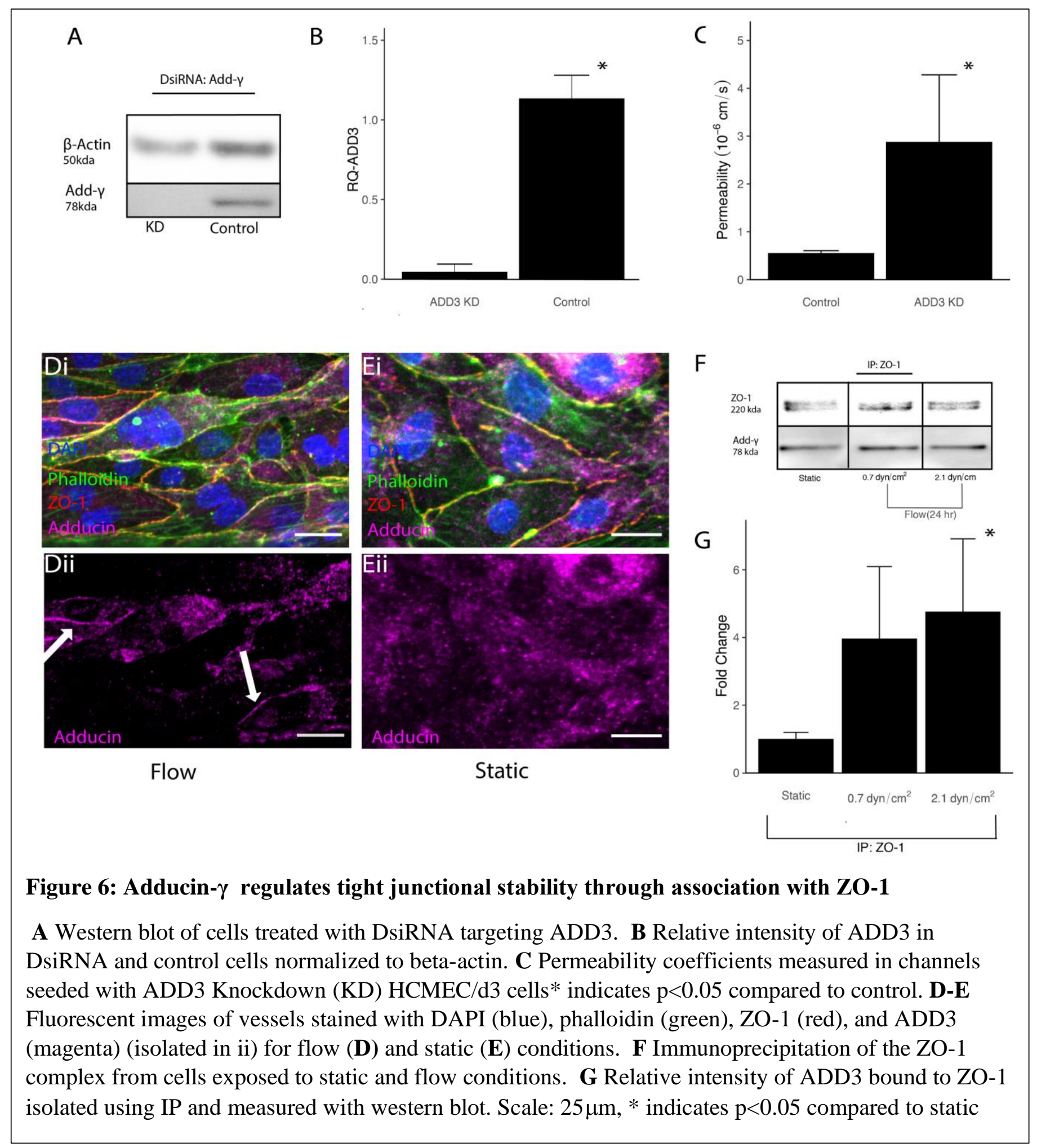




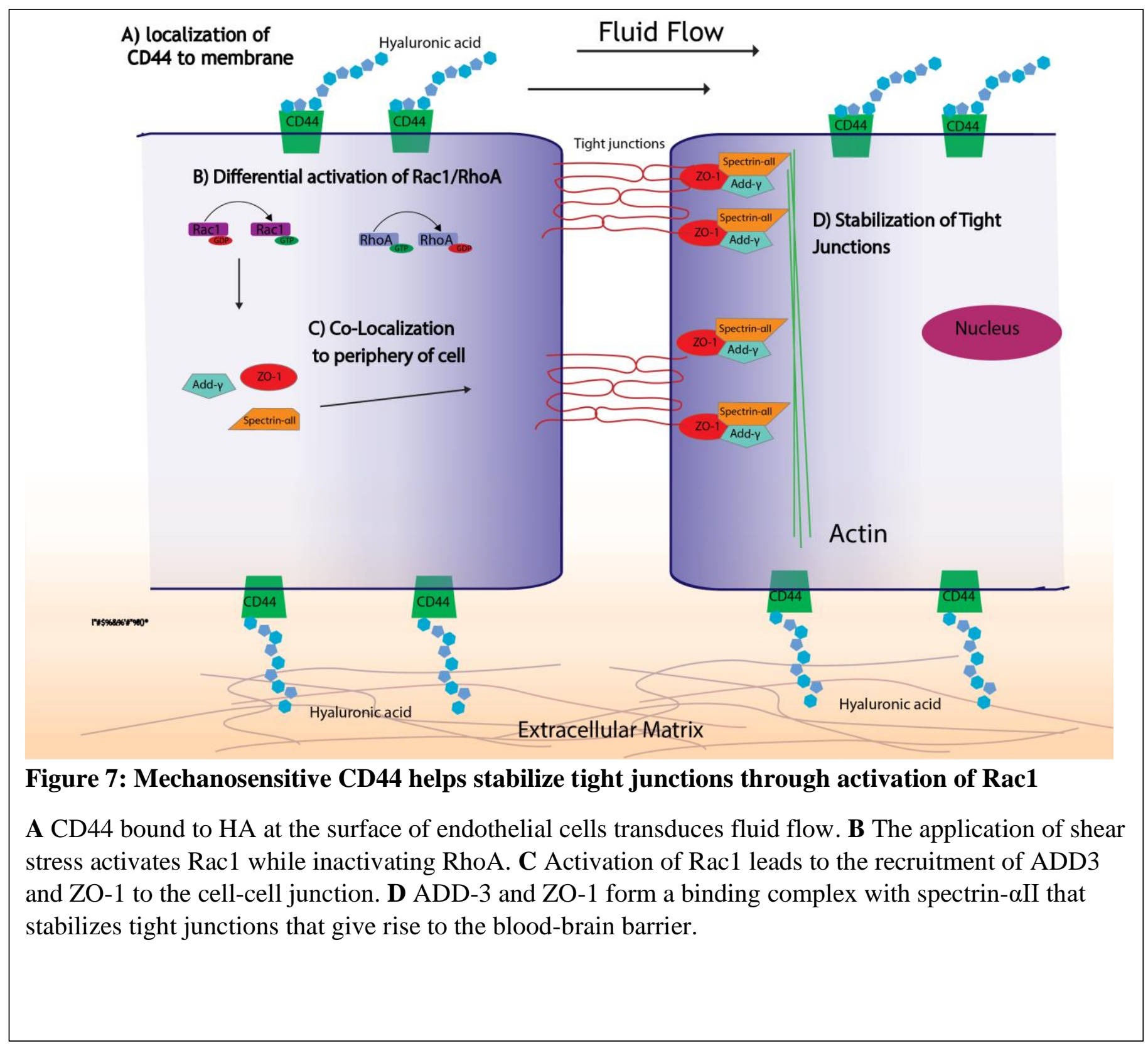




\section{Supplemental Figures}

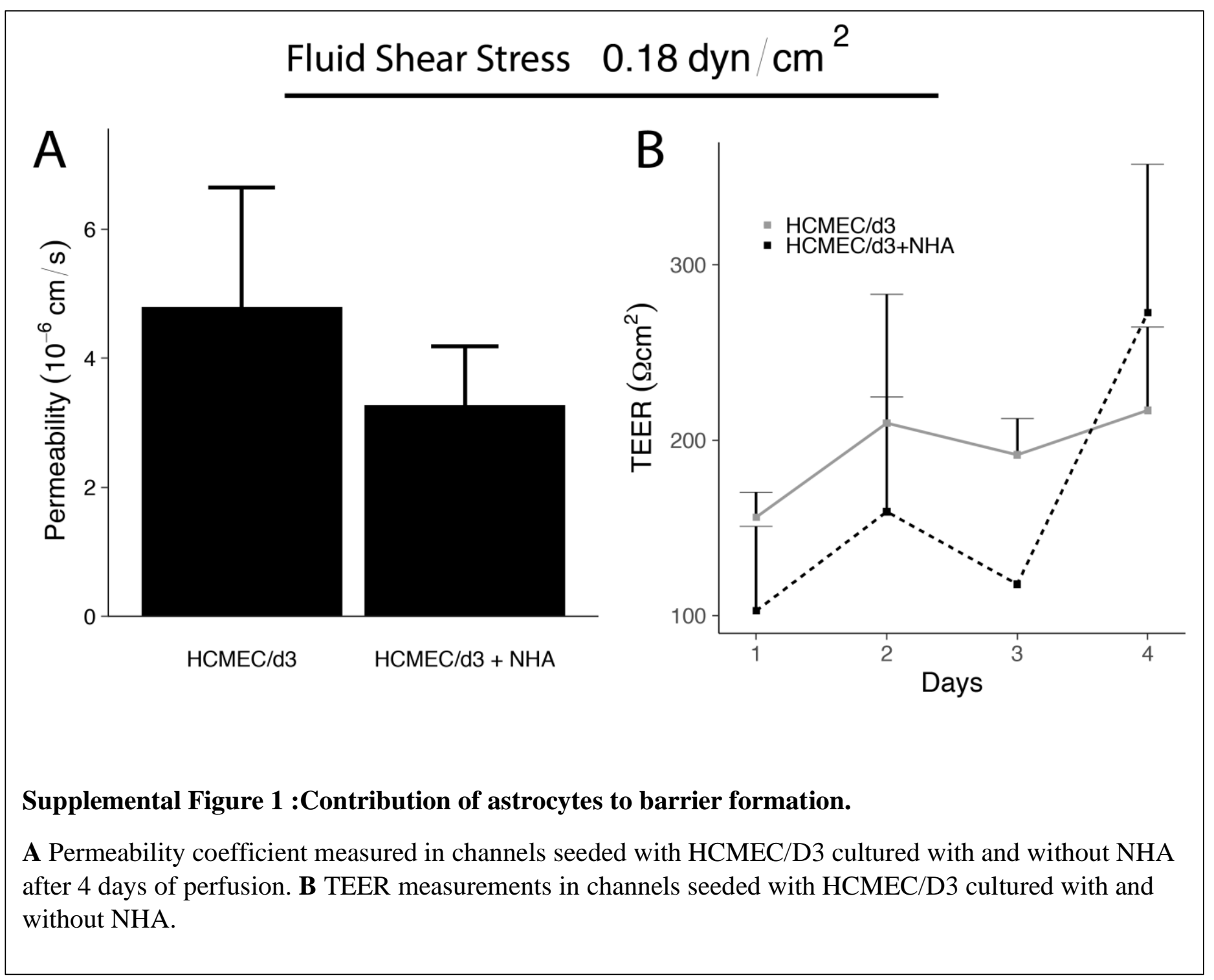



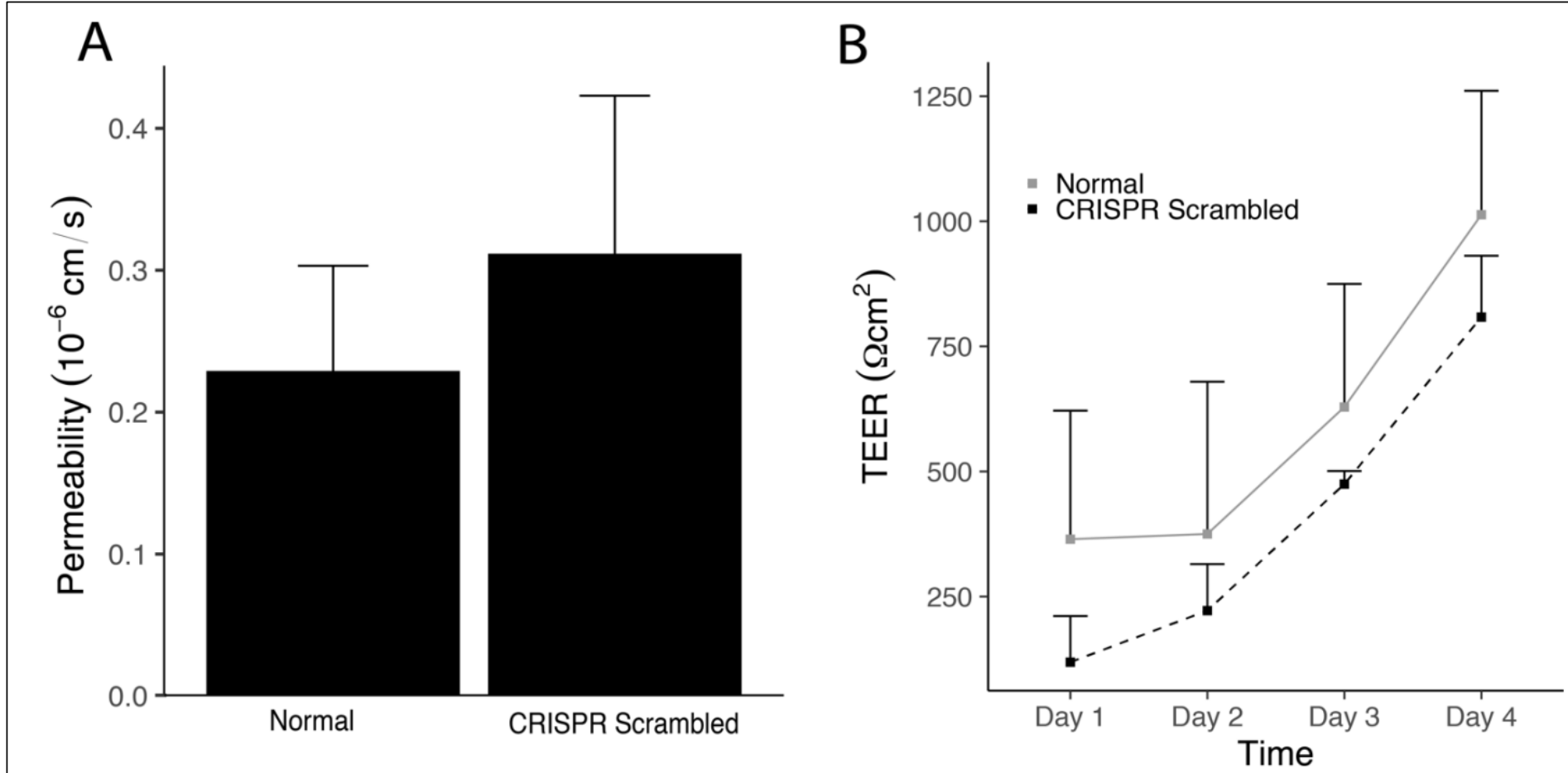

\section{Supplemental Figure 2: Barrier integrity of normal and transfected HCMEC/D3.}

A Permeability coefficients measured in channels seeded with HCMEC/D3 and exposed to $0.7 \mathrm{dyn} / \mathrm{cm} 2$ for four days comparing cells transfected with scrambled CRISPR/Cas9 plasmids with normal cells. B TEER measurements for channels seeded with both normal and transfected cells. 
bioRxiv preprint doi: https://doi.org/10.1101/2020.01.28.924043; this version posted January 29, 2020. The copyright holder for this preprint (which was not certified by peer review) is the author/funder, who has granted bioRxiv a license to display the preprint in perpetuity. It is made
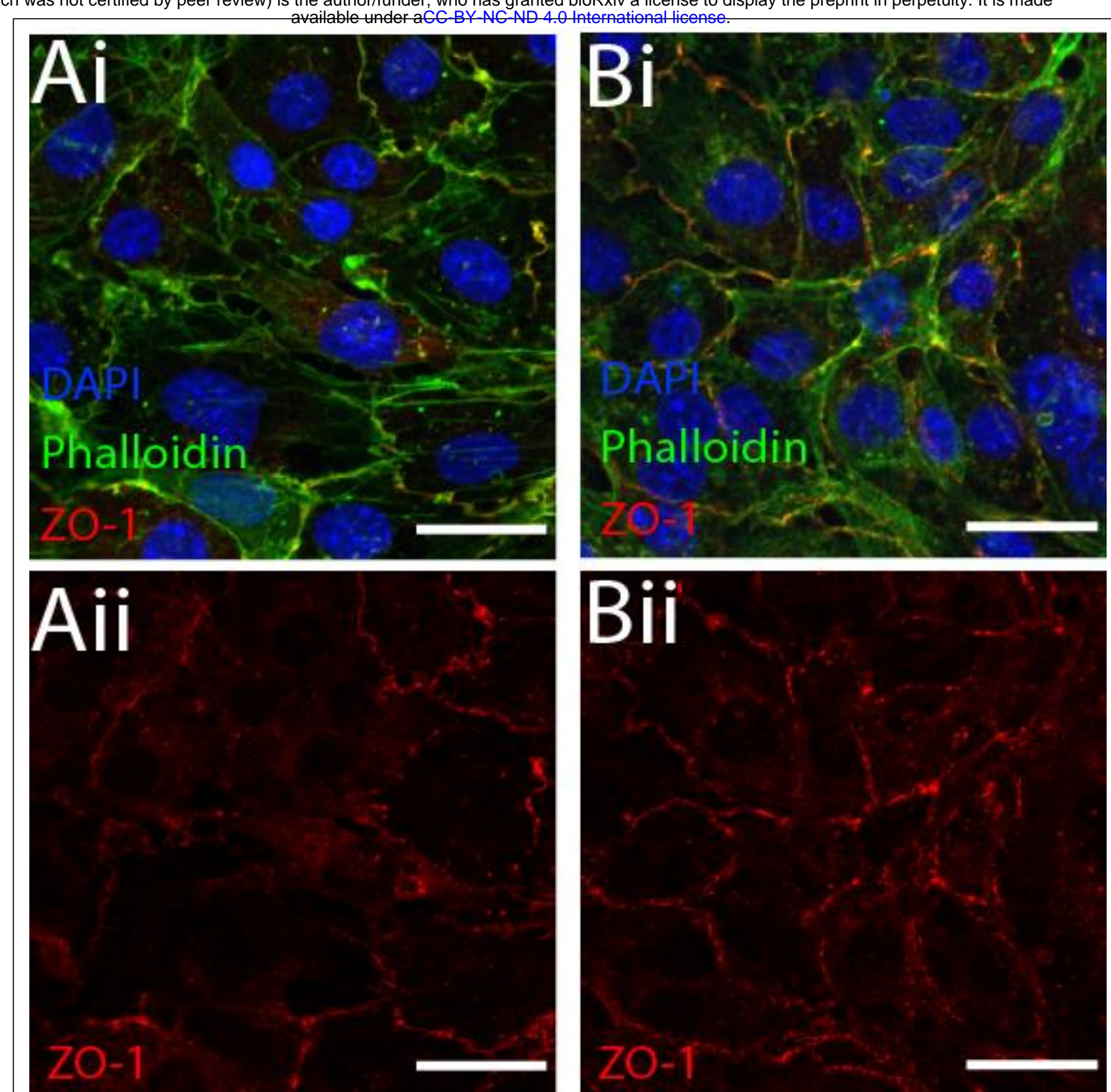

Supplemental Figure 3: ZO-1 localization in cell monolayers used for immunoprecipitation experiments

A-B Monolayers stained for DAPI(blue), phalloidin(green), and anti-ZO-1(red) (isolated in ii) for static (A) and shear (B) conditions after 24 hours. Scale $=25 \mu \mathrm{m}$ 


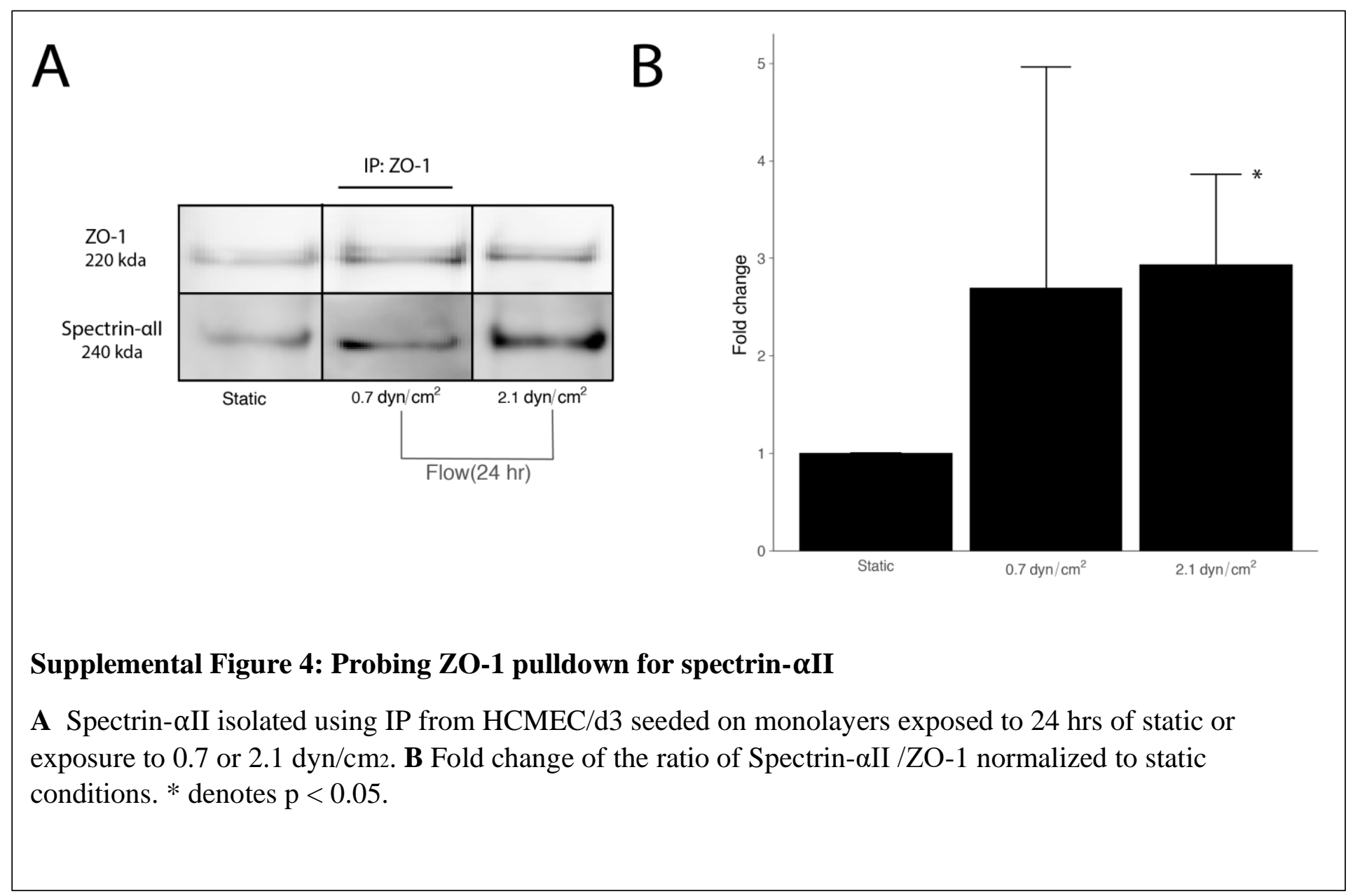

